\section{Contributions of vascular and Alzheimer's disease pathology to dementia}

Although Alzheimer's disease (AD) is frequently cited as the most common type of dementia, the relative contributions of vascular and neurodegenerative pathology to clinical dementia have been actually obscure. The systematic review of studies reporting clinicopathologic data of dementia cases sheds important light on this issue [1]. Ten reports were analyzed, and altogether they included 2856 individuals, 1544 clinically demented and 1312 nondemented, with postmortem neuropathologic diagnosis.

The results showed that both vascular-type only and Alzheimer-type only pathologies were associated with similar prevalence of clinical dementias, whereas the greatest risk of clinical dementia was observed among those with mixed pathologies (AD plus vascular). Neuropathologic analyses actually suggest that any multipathology (AD, vascular, or Lewy-related) increases the risk of dementia significantly [2].

We have earlier sought to discern various dementia types and their risk factors in our longitudinal study of older men (Helsinki Businessmen Study [HBS] [3]). The analyses were based on diagnoses (not only as cause-of-death) and narratives in death certificates [4]. We defined as "pure" AD, if only $\mathrm{AD}$ was noted without any reference in the death certificate to atherosclerotic cardiovascular disease (ASCVD); as pure vascular, if dementia plus any ASCVD was noted; as "mixed" if both AD and ASCVD were mentioned in the death certificate. Minority of cases had other specific dementia diagnosis or undefined dementia without concomitant ASCVD or AD.

The distributions of clinicopathologic diagnoses of dementia types in the systematic review and clinical diagnoses in the HBS had a striking resemblance, and they are compared in Table 1.

Conflict of interest: T.E.S. reports various types of cooperation (educational, research, and consultation) with several companies marketing cardiovascular drugs including Amgen, AstraZeneca, Merck, Orion Pharma, Pfizer, Servier. Minor stock in Orion Pharma (listed company). P.J.T. declares no conflict of interest related to this letter.

*Corresponding author. Tel.: +358-40-672-4533; Fax: $+358-85375661$.

E-mail address: timo.strandberg@oulu.fi
In the HBS, we could also relate dementia diagnosis at median age of 75 years to ASCVD risk factors measured in midlife, at median age of 42 years. In adjusted analyses only serum cholesterol was significantly related to dementia with pure vascular or mixed features, whereas none of midlife ASCVD risk factors, including glucose, were related to pure AD during follow-up to old age [4].

The data from the systematic review and HBS support prevention possibilities in more than half of dementia cases. However, one quarter of cases seem to be because of Alzheimer-type only dementia, which still eludes both preventive and curative treatments. Immune system is a probable contributor that deserves attention [5].

\section{Acknowledgments}

The Helsinki Businessmen Study has been supported by Gustaf och Victoria Frimurarestiftelse; VTR-funding of the Helsinki University Hospital (TYH 2014245; 2015211); and the Academy of Finland (grant number 311492). The sponsors had no role in the design or conduct of the study; collection, management, analysis, and interpretation of the data; or preparation, review, or approval of the manuscript.

Timo E. Strandberg*

Clinicum and Helsinki University Hospital, University of Helsinki, Helsinki, Finland University of Oulu, Center for Life Course Health Research, Oulu, Finland

Pentti J. Tienari Clinicum and Helsinki University Hospital, University of Helsinki, Helsinki, Finland

Table 1

Comparison of distributions of dementia types in the systematic review [1] and the Helsinki Businessmen Study [4]

\begin{tabular}{lll}
\hline & $\begin{array}{l}\text { Systematic } \\
\text { review of } \\
\text { clinicopathologic } \\
\text { studies }\end{array}$ & $\begin{array}{l}\text { Helsinki } \\
\text { businessmen } \\
\text { Study }\end{array}$ \\
Type of dementia & 24 & 25.5 \\
\hline Alzheimer's disease & 26 & 22.5 \\
Vascular dementia & 27 & 34.5 \\
Mixed Alzheimer's & & \\
$\quad$ disease plus vascular & 7 & 3.8 \\
Lewy body disease & 16 & 13.7 \\
Other & &
\end{tabular}




\section{References}

[1] Azarpazhooh MR, Avan A, Cipriano LE, Munoz DG, Sposato LA, Hachinski V. Concomitant vascular and neurodegenerative pathologies double the risk of dementia. Alzheimers Dement 2018;14:148-56.

[2] Tanskanen M, Mäkelä M, Notkola I-L, Myllykangas L, Rastas S, Oinas M, et al. Population-based analysis of pathological correlates of dementia in the oldest old. Ann Clin Transl Neurol 2017;4:154-65.

[3] Strandberg TE, Salomaa V, Strandberg AY, Vanhanen H, Sarna S, Pitkälä K, et al. Cohort profile: the Helsinki Businessmen Study (HBS). Int J Epidemiol 2016;45. 1074-1074h.
[4] Rantanen K, Strandberg AY, Salomaa V, Pitkälä K, Tilvis RS, Tienari $\mathrm{P}$, et al. Cardiovascular risk factors and glucose tolerance in midlife and risk of cognitive disorders in old age up to a 49-year follow-up of the Helsinki Businessmen Study. Ann Med 2017; 6:462-9.

[5] Steele NZ, Carr JS, Bonham LW, Geier EG, Damotte V, Miller ZA, et al. Fine-mapping of the human leukocyte antigen locus as a risk factor for Alzheimer disease: a case-control study. PLoS Med 2017; 14:e1002272.

https://doi.org/10.1016/j.jalz.2019.04.004 